\title{
O Menemismo como Política Econômica: \\ a Argentina "segura" em âncoras
}

\author{
Mário Luiz N eves de Azevedo ${ }^{*}$ \\ Afrânio M endes C atani
}

Resumo: O objetivo deste artigo éanalisar a política econômica adotada pelos governos de Carlos Saúl Menem (1989-1999) na Argentina. Desenvolvendo como referencial de política econômica o liberalismo ortodoxo, Menem coloca em andamento uma economia baseada nos princípios de mercado, destacando-se um vertiginoso ritmo de privatizações, a redução das tarifas de importação, rígidas ações nos campos fiscal e monetário, a eliminação de subsídios, o fortalecimento do sistema de arrecadação govemamental, a desregulamentação geral dos contratos, 0 incentivo à precarização do trabalho eà flexibilização das relações laborais. Isso leva, paulatinamente, à deterioração e ao encarecimento dos serviços públicos já privatizados, bem como a uma crise social e política de grandes proporções, desembocando na renúncia do presidente Femando De La Rúa, em dezembro de 2001.

Palavras-chave: Argentina, menemismo, política econômica, liberalismo, neoliberalismo.

Abstract: This article intends to analyze the economic policy adopted by Carlos Saúl Menem governments (1989-1999) in Argentina. By developing orthodox liberalism as a reference to economic policy, Menem supports a free market economy, especially with some measures: high-speed privatization process, reduction of imports taxes, stressed fiscal and monetary adjustment, cutting of governmental subsidies, strengthening the tax system, general desregulamentation of contracts, and encouraging labor precarization and flexibilization. Consequently, newly privatized public services become expensive and lose quality, prompting a huge social and political crisis, which ends with resignation of President Fernando De La Rúa in December 2001.

Keywords: Argentina, menemism, econmic policy, liberalism, neoliberalism.

\footnotetext{
*Professor da Universidade Estadual de Maringá (UEM). E-mail: azeved01@ universiabrasil.net

** Professor da Faculdade de Educação da Universidade de São Paulo (FE-USP) e no Programa de Pós-Graduação em Integração da América Latina (PROLAM-USP).E-mail: amcatani@ usp.br
} 


\begin{abstract}
"A solução éa dolarização. H á dois anos venho pregando a necessidade de um acordo monetário com os Estados U nidos para que o dólar seja a moeda correntena Argentina. Pensamos aténa possibilidade de o dólar vir a ser a moeda comum em todo 0 continente, à medida que avance o projeto de estabelecer uma zona de livre comércio nas Américas. Seria uma grande solução para a nossa economia euma esperança de estabilidade (...). I sso não causa o mínimo estrago na soberania, como acham alguns tolos que não entendem nada do assunto (...). Com 0 dólar como moeda corrente, a Argentina estará livre dessas incertezas e se incorpora à economia dos Estados U nidos (M enem, 22 nov. 2000, internet).

“Permitir que o mecanismo de mercado seja o único dirigente do destino dos seres humanos e do seu ambiente natural, e até mesmo 0 árbitro da quantidade e do uso do poder de compra, resultaria no desmoronamento da sociedade" (Polanyi 1980: 85).
\end{abstract}

\title{
Introdução
}

A Argentina foi um dos países da América Latina que, na década de 1990, implementou com grande radicalidade uma agenda reformista liberal ortodoxa. Torna-se pertinente lançar um olhar meridional à política econômica adotada pel os $G$ overnos de C arlos Saúl M enem (1989-1999) ${ }^{1}$ - afinal, a Argentina é o principal parceiro do Brasil na entificação do M ercosul e percebe-se que, historicamente, ambos os países, segundo suas tomadas de rumo na política e na economia, influenciam-se mutuamente e influenciam os outros países da América do Sul.

0 menemismo no poder, assumindo uma identidade neodireitista, adotou como referencial de política econômica o liberalismo ortodoxo. M enem não estava isolado ao assumir tal posicionamento no campo da economia política, poiso final do século XX foi pródigo em governos que adotaram reformismos de tipo neoliberal. A esse respeito, são muitas os denominações do movimento de reformas em direção ao mercado. Poderia ser designado de pensamento único, novo radicalismo liberal, novo liberalismo, nova ortodoxia, hiper-liberalismo, liberalismo ortodoxo, mercadofilismo ou neoliberalismo. Sem qualquer

\footnotetext{
${ }^{1}$ Omenemismo político-econômico não sofreu uma solução de continuidade com o seu sucessor Fernando de La Rúa (2000-2001). Somenteapósa derrocada do frustrado Governo De La Rúa, pode se dizer que o neoliberalismo foi colocado em xeque na Argentina.
} 
prejuízo conceitual e devido ao uso mais ou menos comum do termo, opta-se aqui por denominar o reformismo econômico privatista do final do século XX deneoliberalismo.

\section{O neoliberalismo: algumas aproximações}

0 neoliberalismo, no máximo, pode ser considerado uma vertente do liberalismo, o que significa dizer que o atual liberalismo ortodoxo propagandeado pela nova direita não pode ser confundido com o liberalismo clássico. 0 liberalismo, em sua versão política, era fundamentalmente defensor da cidadania. $N$ ão é excesso de zelo recordar o lema da Revolução Francesa: Liberdade, I gual dade e Fraternidade.

No campo econômico, o pensamento liberal deu forma teórica a um modo de produzir que tinha o trabalho livre como conteúdo e o mercado como meio de encontro dos possuidores de mercadorias. D essa maneira, o liberalismo econômico foi a ideologia justificadora das novas relações de produção. A burguesia tevena teoria liberal o substrato ideológico da sua revolução política e econômica. Ponderam Marx e Engels, no célebre M anifesto do Partido Comunista: "A burguesia desempenhou na história um papel eminentemente revolucionário. O nde quer que tenha conquistado o poder, a burguesia calcou aos pés as relações feudais, patriarcaise idílicas" (1979: 23).

As máximas do liberalismo econômico, lai ssez-faire e lai ssez-passer, demonstram que o individualismo é a sua tônica. Isso revela que a ordem liberal dá margens, por um lado, a confundir-se com o egoísmo possessivo e, por outro, a denotar-se que a lógica da liberdade pode tirar o indivíduo do marasmo social vivido no ancien regime, isto é, o homem comum teria a possibilidade de conquistar a identidade de homem livre, que antes era um ente subsumido na servidão.

O s pensadores neoliberais consideram-se herdeiros do liberalismo clássico, porém há uma distância histórica entre os dois. Primeiro, o neoliberalismo não compreendequal quer componente de humanismo; ao contrário, sua lógica interna de funcionamento é movida pelo princípio da competição entre os seres humanos, como se a relação entre cidadãos fosse simplesmente uma relação comandada por uma ética darwinista. $\mathrm{H}$ ayek, uma das principais referências do neoliberalismo, afirma:

“D escobrir o significado do quese costumachamar dejusiça sodal tem sido, hámais de dez anos, uma das minhas maiores preocupações. $N$ ão consegui esse intento - ou me Ihor, chegue à conclusão de que, com referência a uma sociedade de homens livres, a expressão jusiça social não tem o menor significado." (apud Butler, 1987: 89)²

\footnotetext{
${ }^{2}$ Anegação de significado à expressão justiça social deve se a duas razões: ao fato de o neoliberalismo, essencialmente, não discutir valores sociais (no sentido axiológico) e, também, por defender, fundamentalmente, que as soluções das questões sociais devam ser resolvidas na esfera do mercado.
} 
Segundo, a democracia évista pelos neoliberais com desconfiança e não éconsiderada um valor universal eirrestrito. Anderson auxilia a fazer a necessária delimitação do campo:

“(...) a democracia em si mesma (...) jamais havia sido um valor central do neoliberalismo. A liberdade e a democracia, explicava $\mathrm{H}$ ayek, podiam facilmente tornar-se incompatíveis, se a maioria democrática decidisse interferir com os direitos incondicionais de cada agente econômico de dispor de sua renda e de sua propriedade como quisesse". (1995: 19-20).

Terceiro, em época de capitalismo monopólico, soa como farsa falar em livre concorrência, quando é sabido que o mercado édominado por um pequeno número de mega-empresas. $\mathrm{N}$ a realidade, o capitalismo competitivo está circunscrito ao mundo dos pequenos e médios empreendimentos. 0 mundo dos grandes negócios está concentrado, de maneira oligopólica, nas grandes multinacionais. 0 Programa das N ações U nidas para o D esenvolvimento (PNUD ), em Relatório de D esenvolvimento Humano de 1999, revela que

"O s mercados mundiais estão cada vez mais dominados pelas multinacionais. Segundo as estimativas, as suas subsidiárias no estrangeiro chegaram a faturar 9,5 trilhões de dólares em 1997. As multinacionais agregaram $7 \%$ do PIB mundial em 1997, contra 5\% em meados dos anosoitenta. No total das exportações mundiais, as multinacionais também aumentaram sua participação, passando de um quarto no fim dos anos oitenta para um terço em 1995. As multinacionais baseadas nos Estados U nidos participaram com mais de um quarto do PIB americano: US\$ 2 triIhões sobre um total de U $\$ 7,3$ trilhões" (PN UD, 1999: 31-32).

Para que se possa ter condições de perceber tal magnitude, o mesmo Relatório do PNUD traz uma tabela comparativa entre o faturamento de al gumas multinacionaise o PIB de certos países.

\begin{tabular}{lc}
\multicolumn{2}{c}{$\begin{array}{c}\text { Tabela 1 } \\
\text { Pro de paises e faturamento de } \\
\text { grultinacionais }\end{array}$} \\
\hline Pais ou Multinacional & $\begin{array}{c}\text { PIB ou } \\
\text { fatur amento } \\
\text { (bilhões de } \\
\text { dólares) }\end{array}$ \\
\hline General Motors & 164 \\
\hline Tailândia & 154 \\
\hline Nonuega & 153 \\
\hline Ford Motor & 147 \\
\hline Mitsui \& Co. & 145 \\
\hline Arábia Saudita & 140 \\
\hline Mitsubishi & 140 \\
\hline Polônia & 136 \\
\hline Itochu & 136 \\
\hline Africa do Sul & 129 \\
\hline Royal Dutch/Shell Group & 128 \\
\hline Marubeni & 124 \\
\hline Grécia & 123 \\
\hline Sumitomo & 119 \\
\hline Exxon & 117 \\
\hline Toyota Motor & 109 \\
\hline Wal Mart Stores & 105 \\
\hline Malásia & 98 \\
\hline Israel & 98 \\
\hline Fonte: PNUD, 1999: 32. & \\
\hline
\end{tabular}


Como falar em mão invisível do mercado, a conhecida metáfora de Adam Smith, com um mercado de tal maneira oligopolizado? Contemporaneamente, depois de conhecidas tantas fusões, incorporações e privatizações em grande escala, torna-se delicado aceitar a idéia de que exista concorrência em um cotidiano dominado por poucos e gigantescos complexos empresariais ${ }^{3}$.

Voltando um pouco na História, é quase ponto pacífico que a crise de 1929 somente foi superada com a intervenção do Estado na economia. Portanto, não foi a mão invisível a operadora do milagre da recuperação econômica e social. John $M$ aynard K eynes revelou-se a principal referência teórica da empreitada estatal.

0 Estado, para Keynes, adquire papel de relevância na superação da crise de acumulação capitalista, tornando-se empreendedor, regulador, financiador, árbitro, tocador de obras etc. Em resumo, o Estado passa a ser um grande e necessário criador de demandas.

No início da década de 1970, após os assim chamados "Anos D ourados", o sistema capital ista experimenta outra crise de acumulação. D essa vez, o keynesianismo é colocado à prova, pois, para a elite dirigente, o modelo de planejamento e intervenção estatal estaria esgotado.

$\mathrm{O}$ pensamento de Friedrich von $\mathrm{H}$ ayek e de $\mathrm{M}$ ilton Friedman passou a ser considerado como uma alternativa factível. Conforme $\mathrm{H}$ obsbawm, "o zelo ideológico dos vel hos defensores do individualismo era agora reforçado pela visível impotência e o fracasso de políticas econômicas convencionais, sobretudo após 1973" (1995: 398). 0 neoliberalismo, como programa econômico de governo, ganhou maior crédito político internacional quando $\mathrm{H}$ ayek e Friedman receberem, respectivamente, o Prêmio N obel em 1974 e em 1976 (ibid.: 398).

D o princípio da década de 80 em diante, vários governos optaram por implementar reformas com base no neoliberalismo. Inicia-se com o ditador Augusto Pinochet, no Chile, passa com força aterradora na Inglaterra, com $M$ argaret Thatcher, avança de modo peculiar nos EU A com Ronald Reagan e chega aos anos 90 em vários países, principalmente latino-americanos. M esmo governantes eleitos com plataformas populares (ou populistas), assim que chegam ao poder, cumprem agendas de inspiração neoliberal.

As palavras de C arlos Saúl M enem, então candidato a presidente da República na Argentina, ao comparar o justicialismo ao liberalismo, são suficientes para se reconhe-

${ }^{3}$ De acordo com o PNUD houve, em 1990, 11.300 fusões e aquisições por parte de multinacionais; para 1997, estes números chegaram a 24.600, representando o total de 236 bilhões de dólares (1999: 32). 
cer a contrafação e dimensionar a distância entre o prometido na campanha eleitoral, em 1988, e o realmente efetivado na política econômica argentina nos anos 90 .

“O justicialismo não é liberal na economia, porque o liberalismo considera 0 homem como objeto eo considera como mais uma mercadoria. (...) $\mathrm{N}$ ão se pode apelar para a idéia de um mercado livre de trabalho, pela simples razão de que a força de trabalho humano não é uma mercadoria como as outras. (...) M as não é só por isso que rejeitamos a concepção liberal. R ejeitamo-la também porque esse mesmo liberalismo, que vive postulando os benefícios teóricos da liberdade, exibe-se internacionalmente com vocação imperial. (...) Exigem-nos pôr em caixa nossos déficits fiscais, abrir nossos mercados, ajustar nossa economia. Enquanto isso, desde o N orte incorre-se em fabulosos desequilíbrios, al imenta-se uma corrida armamentista delirante e financiam-se esses mesmos déficits com os capitais recebidos de nações pobres. Por tudo isto - enão por um capricho ideológico - 0 justicialismo rejeita o liberalismo". (M enem apud Ayerbe, 1998: 75).

A América Latina se converteu, no último quartel do século $X X$, em um espaço de variadas experimentações de reformas econômicas que se inscreveram na referência teórica do que se pode chamar de neoliberalismo e que, no final dos anos 80, mais precisamente em novembro de 1989, passou a receber o nomede Consenso deWashington, em referência ao texto sugerido por John W illiamson para o Seminário organizado pelo Insitutefor International Economics, do qual participaram autoridades dos governos norte-americano e de países da América Latina e representantes do FM I, Banco M undial e BID . Constituem-se em princípios do Consenso de Washington:

1. equilíbrio das contas públicas;

2. redução de despesas do Estado;

3. não aumentar impostos;

4. diminuição de gastos com empresas públicas e privadas;

5. liberalização e desregulamentação da economia;

6. abertura comercial;

7. eliminação da discriminação ao capital estrangeiro;

8. privatização das estatais.

W illiamson faz ressalvas na aplicação do Consenso de Washington na Argentina. A despeito de sua defesa de um neoliberalismo radical, o economista norte-americano afirma que o Estado deveria ter regulamentado o funcionamento dos monopólios privados:

Às vezes, o processo foi feito sem considerar coisas que eu teria considerado. Por exemplo, na Argentina, houve privatização dos monopólios sem regulamenta- 
ção. Isso não foi o tipo de proposta que eu estava pensando. Escrevi sobre a desregulamentação pensando em um mercado livre, pensando nas empresas e no mercado trabal hista. Eu não estava tentando negar a importância da regulamentação quando há monopólio ou da regulamentação da saúde e do meio ambiente. $\mathrm{N}$ esse tipo de coisa, acho totalmente diferente. 0 Estado tem papel importante nessas áreas. (W illiamson 2000, internet).

Além disso, o organizador do Consenso de Washington acredita que a questão cambial estava sendo tratada demodo extremado naAmérica Latina - o que vale, em particular, para a Argentina. Afirma W illiamson: "A política cambial mudou nos últimos 10 anos para a doutrina dos dois extremos. $\mathrm{N}$ ão foi isso que eu queria. Eu fal ei da necessidade de uma taxa de câmbio competitiva" (2000, internet).

A Argentina tratou a ferro e a fogo sua política de câmbio fixo. Paradoxalmente, diante de tanta flexibilização econômica adotada nos tempos menemistas, o câmbio foi duramente engessado pelo regime de conversibilidade ${ }^{4}$.

\section{A política econômica dos anos 90 na Argentina}

A política de liberalização econômica da Argentina começou a se efetivar fortemente ao fim do ano de 1989, logo após a posse do G overno deC arlos Saúl M enem, sucessor do Presidente Raúl Alfonsín, o qual antecipou sua saída em cinco meses", em virtude da situação de extrema crise (hiperinflação, dívida externa crescente a taxas e prazos sufocantes, fuga de capitais, baixo nível de reservas internacionais etc. $)^{6}$. Reconhece M enem:

0 objetivo fundamental a que me propus quando assumi os destinos da Argentina em 1989 era fazer um processo profundo de transformação do Estado. Colocamos em andamento uma economia de mercado, estabelecemos uma rígida política no campo fiscal e monetário e reinserimos o país no contexto internacional (M enem, 22 nov. 2000, internet).

\footnotetext{
${ }^{4}$ Advertiu Pierre Salama: "Na Argentina há um elemento a mais: tudo se flexibilizou, com exceção da taxa de câmbio, em virtude da Lei de Conversibilidade" (27 nov. 2000: internet).

${ }^{5}$ De 10/12/1989 para 08/07/1989.

${ }^{6}$ Em 1988, a taxa média mensal de inflação ficou em 14\% e, somente em julho de 1989, a inflação alcançou $200 \%$. Calcula-se que os investidores argentinos tenham entesourado no exterior, nessa época, cerca de 50 bilhões de dólares (Viana 1991: 108). Nosúltimos meses do Governo Alfonsín, a fuga de capitais alcançava a cifra de 1 bilhão de dólares por mês (ibid.: 109).
} 
De acordo com Pablo Gerchunoff e Juan Carlos Torre (1997: 156), embasados em Albert $\mathrm{H}$ irschman, para se entender os passos dados na reforma econômica na Argentina é necessário classificar os problemas em dois grupos: problemas escolhidos e problemas prementes.

A crise hiperinflacionária, por exemplo, era um problema premente, imposto pela conjuntura, que tolhia qualquer espaço de manobra. Tinha que ser resolvida sob o risco de, se não houvesse uma iniciativa decisiva, ocorrer uma grande desestabilização social. M enem, eleito com uma plataforma denatureza desenvolvimentista ${ }^{7}$ e popular, empurrado pela famosa bandeira do salariazo (de aumentos salariais), preferiu enfrentar os problemas inflacionário, fiscal e de credibilidade internacional, descartando seus planos de campanha eleitoral e tomando o caminho neoliberal.

Para isso, de imediato, M enem exclui qualquer chance dos peronistas assumirem a condução econômica, aceita a indicação para a pasta da Economia de al tos quadros da multinacional Bunge y Born ${ }^{8}$, suspende por 180 dias os programas especiais de incentivo à indústria, obtém autorização para a demissão de funcionários públicos, recebe delegação do Congresso para legislar por decretos, amplia, com o aceite do Legislativo, de cinco para nove o número de membros da Suprema C orte, nomeando mais quatro juízes, einicia o processo de privatização de estatais (ibid.: 158-163). Além disso, empossa como ministro das R elações Exteriores o economista D omingo C avallo, que mais tarde será o ministro da Economia. AYERBE aponta, ainda, outros liberais, com perfil pró-mercado, no governo M enem:

O sindicalista Jorge Triaca para o M inistério do Trabalho, partidário confesso da ideologia liberal, que manteve boas relações com o regime militar, além de ser considerado um freqüente interlocutor da embaixada dos Estados $U$ nidos e dos grandes grupos empresarias; 0 economista liberal G onzales Fraga como diretor do Banco Central; o deputado da U nião de Centro D emocrático (U CD ) Álvaro Alsogaray, principal liderança histórica do liberalismo argentino etradicional inimigo do peronismo, como negociador oficial da dívida externa; a empresária Amalia Fortabat, do grupo Loma N egra, principal produtor de cimento do país, como embaixadora itinerante (1998: 84-85).

\footnotetext{
7 Dizia Menem antes das eleições: "Nossa iniciativa consiste em impulsionar um novo tratamento da dívida externa que inclua a adequação do pagamento de juros em função do crescimento e da quitação do capital, como instrumentos para garantir a capitalização nacional, investir e produzir" (Menem apud Ayerbe 1998: 75). ${ }^{8}$ Miguel Roig, morto uma semana apósa posse, em 14/07/1989, e Néstor Rapanelli (Guillerm 1994: 40). "Dans ce but, Menem conclut dès son entrée en fonction une alliance tacite de gouvernement avec les secteurs libéraux del'Ucédéetles grandes entreprisesau premier rang desquellesla multinationale Bungey Born, qui lui fournit ses deux premiers ministres de l'Économie" (Guillerm 1994: 32).
} 
M enem passa a dispor de forte liderança no interior do movimento peronista, pois “(...) pela primeira vez desde a morte de Perón, em 1974, o peronismo se unificaria em torno de uma liderança aceita por todas as correntes" (G erchunoff eTorre 1997: 162). Ele desperoniza a política econômica sem desperonizar a sua base de sustentação política. O s poucos dissidentes peronistas não tiveram canais de expressão e a grande maioria colaborou e apoiou as mudanças em curso. Como disseram Gerchunoff eTorre, "o que marcou a diferença crucial do ponto de vista político foi que podia-se abandonar as tradicionais bandeiras do peronismo e escolher novas políticas e alianças, sem perder por isto o respaldo de seus seguidores" (1997: 162).

D essa maneira, o Governo Justicialista imprimiu um ritmo vertiginoso às privatizações: em um ano (até outubro de 1990) quase todas as estatais já tinham sido repassadas à iniciativa privada ; ${ }^{9}$ liberal izou a economia, reduzindo as tarifas de importação em um máximo de 20\%; revogou instrumentos extratarifários (cotas, licenças eproibições deimportações) ${ }^{10}$ e reformou o sistema tributário, concentrando a arrecadação sobre poucos impostos (basicamente, imposto sobre val or agregado e imposto sobre lucros), eliminando subsídios e fortalecendo o sistema de arrecadação, por meio de maiores penas aos sonegadores e mel horia do controle da arrecadação. Ainda, nos estertores de 1989, em 10 de dezembro, o austral sofreu uma desval orização de 53,8\% em relação à moeda norte-americana eastarifas públicas foram majoradas. $\mathrm{H}$ ouve desconforto com estas últimas medidas e o ministro da Economia N estor Rapanelli é destituído no fim desse mesmo mês. Ermán González, o leal amigo do Presidente M enem desde os tempos em que este governou a Província de La Rioja, assume a pasta econômica.

M esmo com todo esse esforço de liberalização econômica radical para conter a inflação ${ }^{11}$, houve outro surto inflacionário. 0 governo, novamente, é premido pela conjuntura econômica. No primeiro dia dejaneiro de 1990, o substituto de Rapanelli

\footnotetext{
${ }^{9}$ É curioso notar que os monopólios não foram quebrados e, para se conquistar interessados nas privatizações, houve a reserva de mercado e a garantia de rendas virtuais (Gerchunoff e Torre, 1997: 165). Outro ponto a se destacar é que 0 Governo de Alfonsín, que tinha uma agenda de privatizações, tentou vender $40 \%$ dos ativos das companhias telefônica e de transporte aéreo. Não obteve êxito, pois enfrentou forte oposição dos peronistas (Gerchunoff e Torre, 1997: 164).

${ }^{10}$ Tarifa média de importação da Argentina

$1989 \quad 1990 \quad 1991$

$26 \% \quad 17 \% \quad 10 \% \quad$ (Fonte: Gerchunoffe Torre 1997: 166).

${ }^{11}$ Entre dezembro de 1989 e março de 1990, a inflação foi reduzida de 200\% para 6\% ao mês.
} 
no M inistério da Economia anuncia o Plano Bonex (bônus externos), que consiste em uma política monetária restritiva e de alongamento compulsório do perfil da dívida pública, convertendo os depósitos a prazo fixo acima de $U \$ 500,00$ (quinhentos dólares) em bônus emitidos em dólar, resgatáveis a longo prazo (dez anos). Este brusco corte da liquidez na economia não foi o suficiente para debelar a inflação definitivamente, pois esta persistiu em uma média de $25 \%$ ao mês. Visando ao combate à inflação e ao aprofundamento do ajuste fiscal, o governo M enem anuncia, em março de 1990, outras medidas. Ayerbe destaca as principais:

- estabelecimento de sistema de afastamento antecipado para funcionários públicos que estejam a até dois anos da aposentadoria, com pagamento de salário pelo período que falta;

- proibição ao Banco Central de financiar o déficit do Tesouro;

- indexação diária dos impostos;

- elevação do imposto sobre o capital em 1,5\% edas retenções às exportações em 5\%;

- prorrogação do prazo de pagamento aos provedores do Estado por sessenta dias sem indexação;

- suspen são de contratações, licitações e compras do setor público;

- asempresas deverão pagar 5\% deimpostossobreseusingressos brutosanuais(1998: 93).

Essas políticas contracionistas não são simpáticas a certos setores do sindical ismo, pois vão de encontro às históricas bandeiras do peronismo. N ão obstante, em setembro de 1990, outras medidas são publicadas:

- o M inistério da Economia assume a administração das empresas sob o controle do M inistério de 0 bras e Serviços Públicos e do M inistério da D efesa;

- suspensão de contratações públicas e implementação de programa de redução de pessoal atingindo vintemil funcionários, por mudanças no regime deindenizações por aposentadoria antecipada;

- definição do cronograma de privatizações (Ayerbe 1998: 95).

Somenteem 1991, após um acúmulo de reservas cambiais durante o ano de 1990, foi possível executar El Plan de Convertibilidad - o Plano Econômico de Domingo Cavallo, que foi nomeado M inistro da Economia em janeiro de 1991. 0 grandemote desse plano foi ancorar a moeda nacional no dólar americano. Criou-se um regime monetário onde 1 peso $=1$ dólar e proibiu-se qualquer emissão monetária sem 0 correspondentelastro em divisas americanas depositado no Banco Central da República Argentina. Assim, o papel do Banco Central reduziu-se drasticamente, limitando-se a ser uma caixa de conversão. 
Esse tipo de câmbio fixo acalmou as expectativas externas, pois já a partir de abril de 1991 astaxas dejuros caíram de 44\% para 22\% ao ano; a inflação começou a descer de forma gradual e sustentada; o governo conquistou novos empréstimos internacionais e alcançou maior êxito político interno, ganhando as eleições parlamentares em fins de 1991 . 0 justicialismo obteve $40,3 \%$ dos votos contra 30,5\% para os radicaisa queda firme da inflação e a estabilidade conquistada constituíram-seem fortes cabos eleitorais que contribuíram decisivamente para a vitória de $M$ enem.

H ouve reativação econômica acompanhada de estabilidade: fez-se pressão informal das autoridades econômicas sobre os empresários contra a remarcação automática de preços; observou-se o fim do imposto inflacionário, aumentando o consumo de bens populares ${ }^{12}$; os depósitos voltaram aos bancos; as linhas de créditos reapareceram; no plano internacional, com o objetivo de reaquecer as economias dos países centrais (devido à recessão) determinou-se, nas economias avançadas, a baixa da taxa de juros, o que levou os investidores internacionais a buscarem melhores rendimentos para seus capitais nos chamados países emergentes. Este movimento foi acompanhado do refluxo dos fundos argentinos aplicados no exterior. Tais vetores fizeram com que a produção crescesse, a arrecadação melhorasse (equilibrando o orçamento fiscal) e a estabilidade econômica se mantivesse.

Entretanto, como contrapartida negativa, a reativação econômica fez aumentar as importações e diminuir as exportações, causando um crescente déficit comercial. Além disso, os níveis de poupança interna, em virtude do alto consumo, diminuíram drasticamente. Desse modo, não fosse a forte entrada de poupança externa, teria havido um estrangulamento na economia.

A Argentina combinou, entre 1991 e 1994, 0 ajuste estrutural com expansão econômica. N este período, o PIB cresceu a uma taxa média de 7,7\% ao ano, o consumo aumentou em $40 \%$ e a inflação teve um forte descenso na seguinte dimensão: em 1991, a inflação estava em $84 \%$ ao ano e desceu, em 1994, a 3,9\%. Em relação à renda, não houve uma melhora em sua distribuição; ao contrário, o segmento dos $10 \%$ mais ricos da população foi o único que ampliou sua participação (G erchunoff e Torre 1997: 176-177).

O utro problema social que se agravou foi o desemprego. M esmo com o forte crescimento econômico, a taxa de desemprego aumentou de 7\%, em outubro de 1992, para 12,2\%, em outubro de 1994 (Gerchunoff eLlach 1998: 445). 0 agrava-

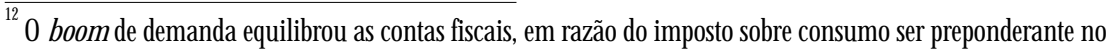
sistema tributário argentino.
} 
mento dosníveis de desocupação pode ser devido a um aumento de produtividadee às dispensas geradas pelas empresas privatizadas, bem como pelo fechamento de vagas nas firmas nacionais afetadas pela concorrência internacional.

A partir desse quadro de estabilidade econômica, isto é, quando a inflação passa a ser medida com um dígito e sendo menor que 5\%, particularmente a partir de 1994,

\section{Tabela 2 Inflação e Desemprego na Argentina}

\begin{tabular}{|ccc|}
\hline Ano & Inflação & Desemprego \\
\hline 1989 & $4.924,0 \%$ & $7,0 \%$ \\
\hline 1990 & $1.344,0 \%$ & $6,3 \%$ \\
1991 & $84,0 \%$ & $6,0 \%$ \\
\hline 1992 & $17,5 \%$ & $7,0 \%$ \\
1993 & $7,4 \%$ & $9,3 \%$ \\
\hline 1994 & $3,9 \%$ & $12,2 \%$ \\
1995 & $1,6 \%$ & $16,6 \%$ \\
\hline 1996 & $0,1 \%$ & $17,4 \%$ \\
1997 & $0,3 \%$ & $13,7 \%$ \\
\hline 1998 & $0,7 \%$ & $12,4 \%$ \\
1999 & $(-) 1,8 \%$ & $13,8 \%$ \\
\hline 2000 & $(-) 1,5 \%$ & $14,7 \%$ \\
\hline
\end{tabular}

*Para o ano de 1989 e 2000 os dados são relativos ao Desemprego Aberto Urbano.

Fontes: Gerchunoff e Llach 1998: 442; Ayerbe 1998: 79; ПNDEC, 04 mar. 2001, internet. o governo Menem deixa de ser premido pela urgência representada pelo risco do retorno hiperinflacionário e começa a tratar de outras questões com um espaço de manobra maior, a partir de ações políticas mais convenientes ao seu governo.

$\mathrm{N}$ esses marcos, o menemismo redesenhou a agenda governamental. Assim, as privatizações do setor elétrico e de gás ocorreram em meIhorestermos (competição efixação detarifas); as importações desenfreadas foram contidas através de algumas medidas de proteção comercial; estimulou-se as exportações; houve iniciativas de promoção industrial e os tratados do M ercosul aprofundaram-se, de maneira vantajosa à Argentina, com uma gama variada de regimes de exceção, sal vaguardas comerciais, cotas e negociações permanentes com os países sócios. D essa forma, a Argentina consegue reverter o déficit na balança comercial. Em 1994, o país exportava US\$15,84 biIhões, passando a exportar U $\$ 20,6$ bilhões no ano de 1995. Suas importações caíram, nesse mesmo período, de US $\$ 19,88$ bilhões para U $\$ 17,9$ bilhões. D e acordo com Ayerbe, entre outras razões, o motivo fundamental que provocou esta situação foi o forte crescimento do saldo positivo na balança comercial com o Brasil.

O s principais fatores que explicam o superávit comercial de 1995, em ordem de importância, são: as exportações ao Brasil, a recessão interna, a melhoria dos preços internacionais dos grãos e da taxa de câmbio em razão da desvalorização internacional do dólar e da apreciação da moeda brasileira (...). As exportações para o Brasil passam a representar $30 \%$ do total, contra $20 \%$ no ano anterior (1998: 155). 
No plano político interno o governo justicialista, por meio de muitas negociações no C ongresso, fez passar a reforma da previdência e privatizou a estatal do petróleo YacimientosPetrolíferosFiscales(YPF), cujo saldo foi utilizado, basicamente, para a liquidação dos passivos previdenciários.

A reeleição de M enem, em março de 1995, deveu-se ao temor da volta da instabilidade. Dessa maneira, o grande cabo eleitoral do menemismo foi a estabilidade econômica. 0 clima eleitoral estava quase no mesmo curso de uma nova crise. A desvalorização do peso mexicano, em dezembro de 1994, refletiu fortemente na Argentina - receava-se o chamado efecto tequila. 0 temor dosinvestidores internacionais da repetição da crise mexicana obrigou a Argentina a aumentar a taxa de juros para conter a forte retirada de recursos do país. Assim, a fuga de capitais, a alta de juros, a queda de investimentos e a baixa de consumo fizeram com que o PIB tivesse uma variação negativa de 2,8\%, em 1995, e o desemprego batessena casa dos 16,6\%.

D essa forma, conforme foi visto antes, o aumento dos preços internacionais de produtos exportados pela Argentina, a recessão interna ea expansão da demanda no Brasil foram os principais estei os de alavancagen s de divisas internacionais da Argenti na. Isso impediu o prolongamento da crise e promoveu a retomada do crescimento econômico. M as, em 1995, determinados setores do governo mais próximos do círculo presidencial, motivados por certa insatisfação presente na sociedade com a recessão havida nesse ano e pelo fato de o ministro da Economia ser um forte candidato à sucessão do seu chefe governamental, começam a solapar a posição de D omingo Cavallo no M inistério da Economia. 0 presidente C arlos $\mathrm{M}$ enem efetiva a mudança na direção da pasta econômica em julho de 1996. RoqueFernández, um dosfundadores do ortodoxo think tank CEM A (Centro de Estudos M acroeconômicos daArgentina), torna-se o substituto do criador do Plano de C onversibilidade ${ }^{13}$.

A Argentina apresentou, em 1996, um crescimento de 5,5\% em seu PIB, porém a taxa de desemprego continuou alta, terminando 0 ano em 17,4\%. 0 saldo na balança comercial, por sua vez, foi de apenas U $\$ 32$ milhões, com exportações no valor de U $\$ \$ 23,760$ bilhões e importações de U $\$ 23,728$ bilhões. O bserva $N$ ochteff que,

em 1996, quando ainda não se havia alcançado o PIB per capita de 1994, as exportações totais cresceram 3,2\%, mas este incremento se deve somente aos equipamentos de transporte, exportados basicamente devido ao regimeautomotriz

\footnotetext{
${ }^{13}$ Ayerbe revela que "Roque Fernández foi o terceiro convidado por Menem para substituir Cavallo, após a recusa deRoberto Aleman eMiguel Angel Broda, nomes demaior expressão erepresentatividadejunto ao establishment nacional einternacional" (1998: 157).
} 
e aos acordos de compensação com o Brasil, já que o restante das exportações caiu 2,8\%. Além disso, as importações aumentaram 18\% (1998: 36).

Tabela 3

Balança Comercial da Argentina com o Brasil (milhões US\$)

\begin{tabular}{|c|c|c|c|}
\hline Ano & Exportação & Importação & Saldo \\
\hline 1990 & 1.423 & 715 & 708 \\
\hline 1991 & 1.489 & 1.532 & $(-) 43$ \\
1992 & 1.671 & 3.367 & $(-) 1.696$ \\
\hline 1993 & 2.814 & 3.664 & $(-) 850$ \\
1994 & 3.655 & 4.325 & $(-) 670$ \\
\hline 1995 & 5.484 & 4.175 & 1.309 \\
\hline 1996 & 6.615 & 5.326 & 1.289 \\
\hline 1997 & 8.127 & 6.914 & 1.213 \\
\hline 1998 & 7.949 & 7.055 & 894 \\
1999 & 5.720 & 5.600 & 120 \\
\hline $1^{\circ}$ sem/2000 & 3.293 & 2.993 & 300 \\
\hline
\end{tabular}

Fonte: Centro de Economia Irtemacional (CEI). 11 feb. 2001. inte me t. htth//Www cei.rurecic.gov.ar.

D urante o segundo mandato do Presidente M enem, o mundo capitalista viveu três significativas crises, colocando em questão a governança inspirada no Consenso de Washington e nas diretrizes do FM I e do Banco M undial. A primeira foi a crise asiática de 1997. A Argentina pouco sentiu esta crise, pois fechou este ano com um crescimento de $8,1 \%$ no PIB, o desemprego desceu a $13,7 \%$ e a conta comercial ficou negativa em U $\$ 4,02$ bilhões. É importante notar que a Argentina teve um superávit de U S\$1,213 bilhão nas transações comerciais com o Brasil. Vale observar a análise de N ochteff:

Nos cinco primeiros meses de 1997, quando se al cançou uma recuperação do nível do produto de 1994, as importações cresceram $31 \%$, enquanto as exportações aumentaram 12,6\% (novamente devido ao incremento na rubrica de material de transporte - 36,8\% - já que o resto cresceu 5,5\%). Em ambos os anos (1996 e 1997), as exportações cresceram graças à demanda brasileira, pois as vendas externas para o restante do mundo caíram 6,1\%, em 1996, e 0,7\% nos primeiros cinco meses de 1997 (ibid.: 36).

A segunda crise do capitalismo mundializado se deu na Rússia em 1998. N esse ano, a Argentina arrefeceu o seu crescimento, ficando em 3,9\%, o desemprego teve uma pequena baixa, descendeu a $12,4 \%$, e o déficit na balança comercial bateu em 4,971 bilhões de dólares, mas novamente a Argentina obteve um saldo positivo nas trocas com o Brasil de U S\$894 milhões.

A terceira crise do modo neoliberal de governar aconteceu com seu parceiro comercial mais importante. 0 Brasil, com suas contas externas vulnerabilizadas (altos 
déficits na balança comercial e na de contas correntes), experimentou uma intensa demanda de moeda forte, logo no início de 1999, efoi obrigado a desvalorizar o real. $\mathrm{N}$ ão poderia ser pior para a Argentina; afinal, com o seu maior parceiro em recessão e com o real depreciado, tornou-se mais difícil colocar suas mercadorias no Brasil. M esmo assim, vendeu U $\$ \$ 120$ milhões a mais do que comprou do Brasil, a sua taxa de desemprego atingiu 13,8\% e o PIB apresentou uma variação negativa de 3\%. (Centro de Economia Internacional, 14. fev. 2001)

A passagem de 1999 para 2000 foi o marco da transição do G overno Justicialista de M enem para o Governo da Alianza de Fernando de La Rúa. No entanto, em 2000, a recessão não concedeu armistício à alternância política, ou melhor, a equipe do presidente De La Rúa, até o início de 2001, não apresentou indícios de ser, realmente, uma governança al ternativa, visando ao crescimento econômico, à implementação de políticas sociais e ao rompimento com o liberal ismo radical; ao contrário, a tônica, no primeiro quartel de seu mandato, foi a manutenção a todo custo do Plan deConvertibilidad. 0 governo de D e La Rúa foi, no campo das políticas econômicas, a continuidade do menemismo sem M enem.

Como exemplo de atuação do governo aliancista, pode-se mencionar, em resumo, parte das medidas do pacote de 29 demaio de 2000 que, em seu conteúdo mais polêmico, promove o corte de salários dos empregados do Estado:

- Redução de salários do funcionalismo público (exceto parajuízes e promotores) corte de $12 \%$ para a faixa salarial entre 1.000 e 6.500 pesos (dólares) e rebaixamento de $15 \%$ nas remunerações superiores a 6.500 pesos (dólares);

- reestruturação de órgãos públicos;

- redução das aposentadorias especiais (de privilégio) - corte de 50\% para os menores de 50 anos e de $33 \%$ para os beneficiários que têm idade entre 50 e 60 anos;

- real ocação orçamentária de 300 milhões de pesos;

- venda de ativos da N ação - participações acionárias do Estado em empresas privatizadas no valor de 800 milhões de pesos;

- Redução de gastos do Poder Legislativo N acional - redução de salários e fechamento da Imprensa do Congresso N acional;

- reforma do Sistema de Saúde - livre escolha do plano de saúde (obras sociais dirigidas pelos sindicatos) e criação de novas seguradoras a partir dejaneiro de 2001;

- reforma da Previdência pública - benefício universal de 80 pesos mensais aos idosos sem outro tipo de renda;

- redução da Prestação Básica U niversal (PBU) para os novos aposentados (para os homens entre 150 e 200 pesos e para as mulheres entre 125 e 150 pesos); 
- incentivo para asmulheresnão se aposentarem aos60 anos. Para cada ano trabalhado após os 60 anos, a mulher receberá 5 pesos; ao completar 65 anos, chegará ao máximo de 25 pesos (de 125 pesos passariaa 150 pesos). (Vales, 30 mayo 2000, internet).

0 pacote do ministro José Luís M achinea não ofereceu um caminho diferente à política econômica adotada nos tempos do hiperliberal ismo menemista. No mesmo sentido, toma atitudes com vistas somente ao cumprimento do ajuste fiscal acertado com o FM I e a continuidade da confiança dos investidores estrangeiros, nem que para isso tenha que ferir a carne dos seus servidores públicos. Isto é confirmado com a anál ise feita pelo economista brasileiro Paulo N ogueira Batista J r.:

0 governo D e la Rúa resolveu agredir seus funcionários. Espera, com isso, recuperar a confiança dos mercados financeiros e dos investidores estrangeiros. (...) D o ponto de vista macroeconômico, a Argentina está sendo levada a fazer o oposto do que deveria. (...) U ma economia nessa situação precisaria, em princípio, de políticas monetárias e fiscais anti-recessivas, que estimulassem a demanda interna. Precisaria, também, de uma desvalorização cambial. Além de ajudar a reativar a economia, a desvalorização tenderia a produzir uma diminuição do déficit no balanço de pagamentos em conta corrente e da dependência em relação a capitais externos. Presa à armadilha construída pela dupla M enem-C avallo, a Argentina não consegue fazer nada disso (01 jun. 2000, internet).

A opinião de dois economistas argentinos, publicadas no Jornal Página/12, com posições ideológicas marcadamente diferentes, pode auxiliar a compreender como foi recebido pela sociedade este pacote e, talvez, revele (ou confirme) quais as perspectivas futuras dos sucessores de $M$ enem.

\section{Quadro 1- Opiniões de economistas sobre o pacote de 29.05.2000}

G uillermo CALVO - "C reio que este pacote permitirá cumprir com o programa acordado com o Fundo. 0 problema residena habilidade do Governo de efetivamente baixar os salários do setor público. Em princípio, as medidas tomadas terão o efeito de tranqüilizar o mercado. D evem trazer, no curto prazo, maior confiança. Com relação à reativação econômica, não sou tão otimista porque se trata de medidas, por princípio, recessivas. Espera-se que a confiança se recupere e que as taxas de juros baixem. Por isso, é vital a maneira como o G overno vai manejar o processo. $\mathrm{N}$ ão se pode esquecer de que Wall Street tem a Argentina na alça de mira e poderia haver perguntas a respeito da dimensão recessiva ou sobre a possibilidade de ocorrerrem tensões sociais. Este pacote é, todavia, uma promessa" (31 mayo 2000, internet). 
Leonardo BLEJER - "Trata-se de um ajuste com características regressivas. 0 mote essencial é a redução de salários, tanto pela diminuição porcentual como pelo fechamento de postos de trabalho. A pesar de que al gumas medidas, como a redução das aposentadorias especiais (de privilégio), possam ser bem vistas pela sociedade, igual ao 'impuestazo', o pano de fundo é que os setores de maior poder econômico ficaram intactos. 0 que se anuncia como aumento do gasto social é, no contexto de graves necessidades existentes, totalmente insuficiente. As reformas estruturais, em particular as que atingem as obras sociais, estão alinhadas com os reclamos do Banco M undial: o objetivo final égerar um espaço maior para as empresas privadas na área de saúde" (31 mayo 2000, internet).

Asuniversidades nacionais não foram afetadas diretamentepelo pacotede29 de maio, mas o governo esperava que elas realizassem um cortevoluntário de suas despesas, no valor equivalente a 40 milhões de pesos. Em reportagem do jornal Página/12 podia-seler:

Apesar de alguns festejarem porque as universidades haviam sido salvas da poda, outros lamentavam por causa do recorte. M esmo sem o anúncio oficial deajuste nos 1,8 bilhão de pesos do orçamento das 36 universidades nacionais, altas fontes do M inistério da Economia asseguraram ao Página/12 que 0 setor deverá perder 40 milhões de pesos (a metade em cada semestre). J osé L uis M achinea calcula que este montante representa o equivalente ao que se arrecadaria se os salários dos docentese funcionários das universidades tivessem sido incluídos no corte geral de salários da administração pública. Como o M inistério daEconomia não podetomar essa medida porque as universidades são autárquicas, a cifra se baseia no total dos recursos e cada universidadefará seu aportecomo Iheconvenha (Lorca, 30 mayo 2000, internet).

A pós reunião entre o M inistro da Educação Juan Llach e os reitores das universidades nacionais, os representantes natos do C onselho Interuniversitário $\mathrm{N}$ acional (CIN ), houve o seguinte acordo de corte voluntário:

Todas as autoridades com cargos de comissão (leiz-se reitores, decanos, secretários [pró-reitores], subsecretários, assessores etc.) aportarão uma parte de seus salários, próximo de $12 \%$, a fim de constituir um fundo solidário de emergência destinado a planos sociais. Ademais, o fundo será alimentado por outras vias: serão abertas contas para que alunos, docentes e funcionários possam depositar sua contribuição; também, recorrer-seá aos recursos próprios gerados pelas instituições com a venda de serviços ou tecnologia. Llach quer quea arrecadação al cance ao menos 20 milhões de pesos (e que seja feita uma diminuição dos gastos burocráticos); entretanto, os reitores mais otimistas sonham apenas em superar a quantia de $10 \mathrm{mi}$ Ihões de pesos (Lorca, 31 mayo 2000, internet). 
D e La Rúa insistiu na política econômica menemista, continuou a acreditar no mercado e na privatização; isto é, o governo argentino permaneceu dependendo da entrada contínua de capitais estrangeiros, empreendendo variados esforços para a rolagem das dívidas externa einterna, patinando na rigidez do câmbio fixo, sacrificando a tudo ea todos pelo equilíbrio fiscal, desregulamentando todos os tratos e contratos, suportando o alto nível de desemprego, incentivando a precarização do trabalho e a flexibilização das relações laborais, solapando as conquistas sociais e o nível de qualidade de vida, assistindo à deterioração e ao encarecimento da distribuição de serviços públicos (já privatizados).

No início de março de 2001, caiu o ministro José Luís M achinea, o governo De La Rúa ainda tentou mais duas vezes, na mesma lógica da busca da confiança do capital internacional, safar-se da crise com dois outros ministros da economia liberais ortodoxos. Primeiramente, foi o efêmero Ricardo Lopez M urphy, de 5 de março a 20 de março de 2001, que não resistiu aos protestos populares após o anúncio de um plano econômico ultra-ortodoxo que previa cortes, por exemplo de U $\$ 1,13$ bilhão na educação (o corte no ensino superior seria de U $\$ 361$ milhões em 2001). D epois foi a vez de D omingo Cavallo, o mesmo ministro da economia de M enem que havia organizado o Plan deC onverti bilidad. I ronicamente, o novo ministro perdera as eleições presidenciais para D e La Rúa, ficando em terceiro lugar.

O governo D e La Rúa não conseguiu tirar o país da recessão. N essa última aposta, depositou esperanças naquele que montara, em tempos menemistas, o imbróglio da conversibilidade e do câmbio fixo, acreditando que o mesmo que atou saberia o segredo de desatar. Em relação à educação, não surpreende o discurso ideológico privatista de Cavallo enquanto candidato presidencial em 1999, quando recebeu $10 \%$ dos votos, que poderia ser assim resumido:

0 fato de queo Estado deva "assegurar o ensino primário" nos termos constitucionais não significa quenecessariamente deva ser o provedor dos serviços educativos através de escolas estatais. (...) 0 acesso gratuito de toda população aos estudos universitários é um caso notável de redistribuição regressiva de rendas. D e acordo com esta visão, propomos em matéria de educação universitária uma combinação de pagamento de anuidades ebolsas de estudo. Todos os estudantes, inclusive os beneficiários de bolsas de estudo, terão o poder de decidir que cursos seguir e em que universidades, públicas ou privadas, com o quese espera uma sadia competição entre todas as instituições e uma melhora da qual idade de ensino. (...) C ada escola conquistará recursos de acordo com a quantidade de alunos que tenha conseguido captar (matricular). Se os resultados são bons, as escolas atrairão mais matrículas e com isto obterão mais recursos. Se os resultados são pobres, os pais 
reclamarão por melhores resultados ou, inclusive, mudarão seus filhos de colégio. (apud Vieiras, 20 mar. 2001, internet).

Cavallo, após reassumir o cargo de $\mathrm{M}$ inistro, obteve junto ao senado argentino, no dia 29 de março de 2001, com 50 votos a favor e 4 contra, plenos poderes para legislar no campo econômico. Com isso, o ministro, defendendo o "déficit zero", promoveu cortes no orçamento, rebaixamento salarial dos servidores públicos e troca "voluntária" de títulos públicos a juros de 7\% ao ano. A sua última cartada foi 0 que ele chamou de "dolarização voluntária". Além da limitação dos saques em 250 dólares semanais (U $\$ 1.000,00 /$ mês), que passou a se chamar "corralito", o decreto 1570, de 01 de dezembro/2001, determina:

- dolarização voluntária (no vencimento) das aplicações em prazo fixo;

- dolarização voluntária dos depósitos bancários;

- proibição de taxas de juros em pesos maiores do que em dólares;

- centralização do orçamento do Estado no M inistério da Economia (todo gasto deve ter a chancela do titular da E conomia);

- dolarização dos novos contratos de financiamento (todos deverão ser consignados em dólar);

- controle pelo Banco Central das transferências de divisas para o exterior, com exceção das provenientes de comércio exterior e do pagamento das faturas de cartão de crédito;

- limitação da posse de dólares pelo turista argentino.

0 economista $\mathrm{D}$ omingo $\mathrm{C}$ avallo, longe de abjurar sua fé no liberalismo ortodoxo, astuciosamente, como se fosse uma partida de futebol de final de campeonato, com o jogo a 1 x 1, tentava preparar uma jogada ensaiada. Em no máximo 90 dias, prazo de validade do decreto 1570/01, o golden-gol deveria acontecer contra o grande adversário, que dentro das regras neoliberais dificilmente seria derrotado. Vale lembrar que time que joga na retranca e na defensiva, em geral, apresenta um futebol sem alma e sem ânimo. Assim, como vencer a recessão, a estagnação, o desemprego, a baixa produtividade, a injustiça social, a desindustrialização e a concentração de renda seguindo uma tática retracionista e entreguista?

Insistindo nessa metáfora futebolística, em artigo publicado dia 09 dezembro de 2001, na revista eletrônica Espaço Acadêmico, intuiu-se: "A pós tantas expectativas, el hincha (o torcedor) argentino não suportará mais uma frustração. N este caso, 0 presidenteFernando de L a Rúa se tornará pequeno para sustentar $\mathrm{D}$ omingo $\mathrm{C}$ avallo. Isto é, se nesta altura do campeonato D e La Rúa se mantiver como dirigente máximo do grande time celeste e branco (...)" (Azevedo, 09 dez. 2001, internet). 
Esse vaticínio concretizou-se antes do $\mathrm{N}$ atal de 2001. Reagindo aos protestos populares, o Governo de Fernando D e La Rúa coloca a Argentina em Estado de Sítio no dia 19 de dezembro de 2001. M esmo sob esse estado de exceção, uma grande massa de pessoas foi às ruas das maiores cidades argentinas e, ao som de cacerolazos (panelaços) e protestos verbais como "Q ué boludos/qué boludos/el estado de ś́tio/lo meten en el ...", força a derrubada de Cavallo na madrugada do dia 20 de dezembro e, no crepúsculo do mesmo dia, fez o presidenteD eL a Rúa ser apeado do poder e partir de helipcóptero da C asa Rosada.

A conclusão do artigo anteriormente referenciado, mesmo tendo sido publicado anteriormente à queda da dupla D e La Rúa/C avallo, continua valendo para os futuros comandantes do escrete argentino: "A Argentina, como todos os outros países latinoamericanos, precisa de crescimento econômico, moeda nativa, industrialização, políticas de emprego e investimentos em educação, saúde e infra-estrutura. O xalá! Q ue a resolução desta crise se oriente a contrapelo das políticas de Washington e marque o fim dos experimentosneoliberaisnaAmérica Latina, levando a Argentina a seliberar das amarras externas e, social elatinoamericanamente, a se 'reargentinizar'" (ibid., 09 dez. 2001).

Como é sabido, a política econômica menemista somente foi descartada após o melancólico e anteci pado fim do governo de Fernando de La Rúa, nas vésperas do $\mathrm{N}$ atal de 2001, a golpes de cacerolazos. Seu sucessor, Adolfo Rodrígues Saá, decretou moratória da dívida no dia seguinte (26 de dezembro 2001), preparando o terreno para retirar a Argentina da armadilha do câmbio fixo e da livre conversibilidade. Porém, Saá não recebeu louros por sua coragem de desatar o nó górdio da economia e, antes disso, renunciou na noite de 30 de dezembro de 2001.

A crise começa a se desfazer com a ascensão de Eduardo D uhal de ao primeiro posto do governo argentino. Após 48 horas de interinato na Presidência da República de Eduardo C amaño (Presidente da C âmara de D eputados), o Senador da República, pela província de Buenos Aires, Eduardo D uhalde, que havia ficado em segundo lugar nas eleições presidenciais de 1999 (perdera para D e La Rúa), assumiu o comando da C asa Rosada em 01 de janeiro de 2002.

D uhalde dá continuidade à moratória da dívida, desval oriza a moeda, ameniza a crise econômica e, como prêmio, faz o seu sucessor nas eleições presidenciais de 2003. N éstor Kirchner, seu candidato, curiosamente disputaria o segundo turno contra M enem. Entretanto, conhecedor do seu alto índice de rejeição, M enem desistiu da disputa em segundo turno. Kirchner torna-se Presidente da República, defende publicamente o M ercosul e inicia a implementação de uma política econômica de corte nacional-desenvolvimentista. 


\section{Considerações finais}

0 menemismo como política econômica acabou sendo descartado após a melancólica saída da C asa Rosada de helicóptero de Fernando de La Rúa no dia 25 de dezembro de 2001. Vale notar que o marco simbólico desse crepúsculo foi a força popular convertida em vigorosos gol pes de cacerolazos. 0 sucessor de D e La Rúa foi o peronista Adolfo Rodrígues Saá, que anunciou uma moratória da dívida no dia seguinte (26 de dezembro 2001). I sto significou um passo certo na retirada daA rgentina da armadilha do câmbio fixo e o fim da livre conversibilidade da moeda. Entretanto, Rodrígues Saá, que desatou o nó górdio do monetarismo ortodoxo, não esperou os resultados, renunciando na noite de 30 de dezembro de 2001.

A pós o interinato de 48 horas na Presidência da República de Eduardo Camaño (Presidente da C âmara deD eputados), D uhalde, atéentão senador eleito por Buenos Aires e ex-vice-Presidente no primeiro mandato de M enem (1989-1995), tornou-se o chefe do governo argentino no primeiro dia de 2002.

Eduardo D uhalde não retrocede quanto à moratória da dívida e permite a flutuação do peso argentino. Como resultado consegue amenizar a crise econômica e, nas eleições presidenciais de 2003, faz seu candidato, o peronista de esquerda N éstor K irchner, o sucessor na Presidência da República.

Enfim, o que poderíamos tirar delição do reformismo menemista? A experiência neoliberal naArgentina, em todos os seus níveis e setores, pode servir de ensinamento às outras nações. Com inspiração em Polanyi, conforme a epígrafe do presente artigo, pode-se afirmar que a sociedade (em qualquer país) não se deve deixar guiar pela "mão-invisível", pelo mercado auto-regulável ou pelos princípios do liberalismo econômico. Hipoteticamente, o império do mundo das mercadorias, caso implantado definitivamente, não poderia ocorrer sem aniquilar a substância humana - o que seria a destruição final da sociedade.

\section{Referências Bibliográficas}

AM IN , S. L'idéologie et la pensée sociale. L'intelligentsia face à la "crise du développement". Canadá, disponível em: 〈ttp://www.alternatives.ca>. Acesso em: 01 set. 1999.

AN D ERSO N, P. "Balanço do neoliberalismo". In: SADER, E.; GEN TILI, P. (org.). Pósneoliberalismo: as políticas sociais e o Estado democrático. Rio de Janeiro, Paz eTerra, 1995, p. 9-37.

AYERBE, L.F. N eoliberalismo e Política Externa na América Latina. São Paulo, Editora U N ESP, 1998. 
AZEVED O, M.L.N . de. "Os passos de Cavallo: dolarização, desvalorização e 'reargentinização' ou ... esperando o 'golden-gol': a Argentina e aúltima jogada de Cavallo". In: Revista eletrônica Espaço Acadêmico, 09 dez. 2001. Disponível em: বttp://www.espacoacademico.com.br/07azevedo.htm>. Acesso em: 11 dez. 2001.

BATISTA JR., P.N. "Autofagia na Argentina”. In: Folha de S. Paulo, 01 jun. 2000, disponível em «tttp://www.uol.com.br/fsp>. Acesso em: 01 jun. 2000.

BO RÓ N , A. Estado, capitalismo e democracia na América Latina. Tradução de Emir Sader. Rio de Janeiro, Paz eTerra, 1994.

BO URDIEU, P. Contrefeux. Paris, Éditions Liber-Raisons d'Agir, 1998.

BUTLER, E. A contribuição de H ayek às idéias políticas e econômicas de nosso tempo. Tradução de C arlos dos Santos Abreu. Rio de Janeiro, Instituto Liberal, 1987.

CENTRO DE ECON OM IA INTERN ACIO N AL (CEI). Banco deD ados. Buenos Aires, 11 feb. 2001. D isponível em: 〈http//www.cei.mrecic.gov.ar>.

FRIED M AN, M. Capitalismo e liberdade. Tradução de Luciana Carli. São Paulo, Abril Cultural, 1983.

GERCH U N O FF, P.; TO RRE, J. C. "Argentina: La política de liberalización económica bajo un gobierno de base popular". In: VELLIN G A, M . (coord.). El cambio del Papel del Estado en América Latina. M éxico, Siglo XXI, 1997.

; LLACH , L. El ciclo dela ilusión y el desencanto: un siglo de políticas económicas argentinas. Buenos Aires, Ariel, 1998.

GUILLERM, G. "Le 'ménémisme', ou les paradoxes d'une logique libérale”. In: D ELAVAUD, A. C.; N EFFA, J. C. L'Argentine: a l'aubedu trois ème millénaire. Paris, IH EAL (Institut des H autes Études de l'Amérique Latine)/ U niversité de la Sorbonne N ouvelle - Paris III, 1994, p. 29-40.

HAYEK, F. A. O Caminho da servidão. (1 $1^{\text {a }}$ ed.: 1943). Rio de Janeiro, Instituto Liberal, 1984.

H O BSBAW M , E. Era dosExtremos o breveséculo XX: 1914-1991. Tradução deM arcos Santarrita. São Paulo, C ompanhia das Letras, 1995.

IN DEC (Instituto N acional de Estadística y Censos). Banco de D ados. D isponível em \http://www.indec.mecon.ar>. A cesso em 04 mar. 2001.

KEYN ES, J.M . A teoria geral do emprego, do juro eda moeda. Inflação e deflação. ( $1^{\text {a }}$ ed.: 1936). Tradução de Rolf Kuntz. São Paulo, N ova Cultural, 1985.

LORCA, J. "No hubo recorte pero sí ajuste en las universidades". In: Página/12, Buenos Aires, 30 mayo 2000. D isponível em: 〈http://www.pagina12.com.ar>. Acesso em: 30 mayo 2000.

“Los rectores abren la billetera”. In: Pági na/12, BuenosAires, 31 mayo 2000. D isponível em: 〈http://www.pagina12.com.ar>. Acesso em: 31 mayo 2000. 
M ARX, K.; EN GELS, F. 0 manifesto do Partido Comunista. (1 ${ }^{a}$ ed.: 1848) (O bras Escolhidas, v. 1). São Paulo, Alfa-O mega, 1979.

M EN EM , C.S. Discurso na América's Society (antes do pronunciamento na Assembléia da ONU), Nova York, 1989. Disponível em: <http:// www.carlossaulmenem.com>. Acesso em: 09 dez. 2000.

.Entrevista a Raul Juste Lores. "A solução éo dólar". In: Veja - Revista semanal, São Paulo, 22 nov. 2000. Disponível em: বttp://www2.uol.com.br/veja/ 221100/entrevista.html>. Acesso em: 19 jan. 2001.

N O CH TEFF, H .(org). La economía argentina a fin desiglo: fragmentación presentey desarrollo ausente. Buenos Aires, Flacso/Eudeba, 1998.

PN U D (Programme des N ations U nies pour le développement). Rapport M ondial sur leD éveloppement H umain 1999. Paris/Bruxelles: D eBoeck U niversité, 1999.

PO LAN YI, K. A G randetransformação. Asorigensda nossa época. Tradução de Fanny Wrobel. Rio de Janeiro, Campus, 1980.

SALAM A, P. "Entrevista”. In: Página/12, Buenos Aires, 27 nov. 2000. D isponível em: 〈http://www.paginal2.com.ar>. Acesso em: 27 nov. 2000.

SM ITH , A. Inquérito sobre a natureza eas causas da riqueza dasnações. $2^{a}$ ed. Tradução deTeodora C ardoso e Luís C ristovão de Aguiar. Lisboa, Fundação Calouste Gulbenkian, v. 1, 1980.

VALES, L. "Todas las medidas del paquete". In: Página/12, Buenos Aires, 30 maio 2000. D isponível em: «ttp://www.paginal2.com.ar>. Acesso em: 30 maio 2000.

VIAN A, F. Argentina: civilização e barbárie. São Paulo, Atual, 1991.

VIEIRAS, N. "No digas que no te avise". In: Página/12, Buenos Aires, 20 mar. 2001. D isponível em বhttp://www.pagina12.com.ar>. Acesso em: 20 mar.2001.

WILLIAM SO N, J. "Entrevista a C arlos Tautz". In: 0 utra Globalização. Jornalismo estratégico, análises e notícias sobre as mudanças no planeta, ano I, nov. 2000. D isponível em: «ttp://www.outraglobalizacao.jor.br>. Acesso em: 02 jan. 2001. 
Mário Luiz N eves de Azevedo eAfrânio M endes Catani - CadernosPRO LAM /U SP (ano 2 - vol. 2 - 2003), p. 111-133 